ESPAÇO TEMÁTICO: VIOLÊNCIA, SAÚDE E CLASSES SOCIAIS

\title{
Ensaio sobre psicodinâmica do trabalho
}

\author{
João Areosa ${ }^{1}$ \\ https://orcid.org/0000-0001-5112-1521 \\ ${ }^{1}$ Escola Superior de Ciências Empresariais do Instituto Politécnico de Setúbal, Centro Interdisciplinar em Ciências Sociais \\ da Universidade Nova de Lisboa, Lisboa, Portugal
}

\section{Ensaio sobre psicodinâmica do trabalho}

Resumo: A saúde mental no trabalho está diretamente relacionada com a forma como os trabalhadores percecionam os múltiplos aspetos (positivos e/ou negativos) relacionados com a sua atividade laboral. A abordagem da psicodinâmica do trabalho trata precisamente das consequências do trabalho na saúde mental dos trabalhadores, nomeadamente no prazer que suscita ou no sofrimento que produz. O objetivo deste texto é debater o mundo do trabalho a partir desta perspetiva, a qual tem oferecido inúmeros conhecimentos sobre esta complexa realidade.

Palavras-chave: Trabalho. Saúde mental. Psicodinâmica do trabalho.

\section{Essay about psychodynamics of work}

Abstract: Mental health at work is closely related to how employees perceive the multiple aspects (either positive or negative) of their work activity. The psychodynamic of work approach deals precisely with the consequences of work on the mental health of workers, namely in the pleasure it provokes or the suffering it produces. The purpose of this text is to discuss the world of work from this perspective, which has offered innumerable knowledge about this complex reality.

Keywords: Work. Mental health. Psychodynamics of work.

Recebido em 22.09.2020. Aprovado em 15.12.2020. Revisado em 04.02.2021.

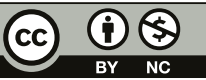

Este é um artigo publicado em acesso aberto (Open Access) sob a licença Creative Commons Attribution NonCommercial, que permite uso, distribuição e reprodução em qualquer meio, sem restrições desde que sem fins comerciais e que o trabalho original seja corretamente citado. 


\section{Introdução}

Temos hoje fortes indícios de que as relações sociais de trabalho estão a ser paulatinamente envenenadas pelo modo de produção capitalista (GAULEJAC, 2007; STANDING, 2014; AREOSA, 2017; MENDES, 2018; ANTUNES, 2018). Seguramente que haverá outras causas, mas esta estará no epicentro do fenómeno. Um dos efeitos mais notórios desta situação pode ser observado quando, em diversas organizações contemporâneas, se verifica que as condições de trabalho (no sentido amplo do termo) são ultrajantes e/ou patogénicas para quem lá exerce a sua atividade profissional (CLOT, 2006; LINHARES; SIQUEIRA, 2014). As exigências organizacionais são cada vez mais elevadas e isso obriga os trabalhadores a lutarem num designado reino da performance para manterem o seu posto de trabalho (DEJOURS, 2015). Entre outros aspetos, isso faz aumentar as patologias da sobrecarga (LIMA; MENDES; COSTA, 2015). A exploração e a autoexploração estão ao rubro, dando origem a uma sociedade do cansaço (HAN, 2017). Sendo o lucro a principal meta das empresas quase todos os golpes se tornam permitidos para se poder atingir as metas e os objetivos. As modernas técnicas de gestão têm produzido múltiplos efeitos iatrogênicos para a saúde dos trabalhadores. O medo e a concorrência dominam o mundo laboral. Verifica-se uma intensificação do trabalho (ROSSO, 2008), mesmo quando as melhorias técnicas e tecnologias fariam supor o contrário. A frustração e a ansiedade aumentam de forma galopante. Os conflitos sobem de tom em várias categorias profissionais (LANCMAN et al., 2012). Naturalmente que tudo isto está na génese do sofrimento provocado no e pelo trabalho (AREOSA, 2018). Aliás, a etimologia de trabalho advém de tripalium (instrumento de tortura utilizado na Idade Média), ou seja, desde a sua origem a palavra trabalho surge associada à ideia de punição, sofrimento ou maldição.

É verdade que nem sempre o trabalho esteve ligado a esta visão negativa. Por exemplo, as doutrinas calvinistas olham para o trabalho como um meio passível de gerar prazer, coesão social e desenvolvimento (WEBER, 2005). Todavia, esta visão está longe de ser dominante. Talvez a história recente da humanidade se reveja maioritariamente na perspectiva partilhada por Freud: "E, contudo, o trabalho, como caminho para a felicidade, é pouco apreciado pelos homens. Eles não se esforçam muito no que lhe diz respeito como o fazem em relação a outras possibilidades de satisfação. A grande maioria não trabalha a não ser pressionada pela necessidade, e dessa aversão natural ao trabalho que os homens têm, decorrem os mais árduos problemas sociais" (FREUD, 1997, p. 267). Paralelamente, é imprescindível não esquecer que a esmagadora maioria da população mundial faz depender o seu sustento a partir do trabalho, isto é, uma enorme classe-que-vive-dotrabalho (ANTUNES, 2008). Numa determinada perspetiva, trabalhar é sinónimo de subsistir. É por isso que o desemprego faz disparar todos os nossos alarmes ancestrais de sobrevivência. É também por isso que o fator trabalho continua a ser central no mundo hodierno. Mas o trabalho, hoje, está a degradar a nossa saúde mental, pelo menos num grande número de situações (DEJOURS, 2013).

Neste contexto é relevante não esquecer qual é o sentido que o trabalho assume na contemporaneidade (ANTUNES, 2018). O trabalho de cada um deveria estar ao serviço da comunidade, mas o capitalismo tem provocado a implosão do mundo do trabalho e a consequente falência de um universo social coerente. $\mathrm{O}$ capitalismo flexível tem originado uma profunda desestabilização dos empregos estáveis e colocado muitos trabalhadores numa intermitência entre trabalho precário e desemprego. Além de todas as consequências materiais que o desemprego acarreta, ele gera medo, ansiedade, porque faz pairar sobre nós o fantasma da inutilidade (SENNETT, 2006) e isso é absolutamente aterrador para a saúde mental. Em casos extremos questões relacionadas ao trabalho podem até estar na origem de alguns suicídios (DEJOURS; BÈGUE, 2009), os quais representam certamente uma profunda desestruturação das relações sociais de trabalho (DEJOURS, 2017). É possível que um dos maiores desafios que o capitalismo flexível nos coloque seja o de saber quem precisa de nós? Esta pergunta está longe de ter uma resposta imediata, mas se não houver o reconhecimento de que o nosso trabalho é importante, de que exercemos uma função social útil, o nosso ego sente-se perdido no universo social rarefeito, bem como nós mesmos enquanto seres sociais no seio de sociedades individualistas; e as pessoas sentem falta de maior coesão social, de relações humanas sustentadas e de objetivos duradouros (SENNETT, 2001). Para a maioria da população mundial o trabalho é a principal fonte de subsistência, mas tem relegado muitos trabalhadores para a ultraperiferia da existência. Esta conjuntura neoliberal tem degradado a saúde mental dos trabalhadores e a psicodinâmica do trabalho ajuda a desvendar vários fatores que contribuem para esta degradação. 


\section{Psicodinâmica do trabalho: uma abordagem integrada}

Quase toda a obra de Christophe Dejours (mentor da psicodinâmica do trabalho) assenta numa reflexão proficiente sobre a influência do trabalho na saúde mental dos trabalhadores. Este tema é indiscutivelmente importante na atualidade, dadas as múltiplas consequências (positivas e/ou negativas) que podem provocar nos sujeitos, dependendo da forma como organizamos, dividimos e distribuímos socialmente o trabalho. Numa perspectiva histórica, o autor destaca que a psicopatologia do trabalho, a qual surgiu em meados do século passado, se dedicou quase exclusivamente aos efeitos negativos do trabalho.

Porém, durante a década de 1980, chegaram novos contributos para esta discussão, oriundos de outras abordagens disciplinares, nomeadamente a ergonomia, a psicologia, a sociologia, a psicanálise, a medicina e a antropologia (isto só para referir algumas delas). Na década seguinte emerge uma nova disciplina, designada por psicodinâmica do trabalho, onde é ampliado o debate sobre os efeitos do trabalho na saúde mental. Dentro desta renovada concepção, o trabalho deixou de ser apenas observado a partir dos seus fatores negativos, passando também a ser considerado quanto aos aspetos positivos que nos pode proporcionar. Esta perspectiva dualista não é exatamente nova, pois já desde Karl Marx (2010) sabíamos que o trabalho nos poderia oferecer o melhor e o pior para a nossa existência. No entanto, aquilo que parece se constituir como algo realmente novo nesta abordagem é a descoberta da extraordinária influência que o trabalho pode ter sobre a saúde mental, destapando o véu sobre a subjetividade ${ }^{1}$ inerente à forma como cada trabalhador lida com o próprio ambiente laboral, o qual tanto é suscetível de produzir sofrimento, como de gerar prazer $^{2}$. É por esse motivo que o trabalho dificilmente pode ser considerado como um elemento neutro perante a saúde mental (DEJOURS, 2005). Este é um dos aspetos inovadores que a psicodinâmica do trabalho nos tem vindo a transmitir, a partir de um manancial de conhecimentos, simultaneamente, teóricos e empíricos.

Tendo em conta a enorme desregulação do mundo do trabalho atual (precariedade, flexibilidade, desemprego, exploração, intensificação, subcontratação, assédio, isolamento, sobrecarga etc.), provavelmente o maior enigma que a psicodinâmica do trabalho pretende decifrar seja: como é que alguns trabalhadores conseguem manter a sua sanidade mental, numa espécie de equilíbrio, quando em determinadas situações podem ser alvo de profundos ataques procedentes do seu ambiente laboral? Como é possível manter esta aparente normalidade, sem enlouquecer, apesar das inúmeras pressões às quais o trabalhador está sujeito? $\mathrm{Na}$ perspetiva de Dejours, a maioria dos trabalhadores vive numa normalidade sofrente.

A normalidade é interpretada como o resultado de uma composição entre o sofrimento e a luta (individual e coletiva) contra o sofrimento no trabalho. Portanto, a normalidade não implica ausência de sofrimento, muito pelo contrário. Pode-se propor um conceito de 'normalidade sofrente', sendo, pois, a normalidade não o efeito passivo de um condicionamento social, de algum conformismo ou de uma 'normalização' pejorativa e desprezível, obtida pela 'interiorização' da dominação social, e sim o resultado alcançado na dura luta contra a desestabilização psíquica provocada pelas pressões do trabalho (DEJOURS, 1999, p. 36).

É pertinente lembrar que o atual modelo económico - capitalismo flexível — tem corroído o nosso caráter (SENNETT, 2001) e as suas políticas neoliberais estão a dar origem a uma verdadeira catástrofe social, onde podemos incluir, por exemplo, diversas assimetrias que estão na base da pobreza e da exclusão, além de promoverem uma competitividade empresarial exacerbada, reestruturações desastrosas, demissões e precariedade (SENNETT, 2006; GAULEJAC, 2007; STANDING, 2014; AREOSA, 2017; MENDES, 2018). Perante este contexto desolador de injustiça social seria expectável observarmos muitos trabalhadores a entrarem em descompensação psíquica, mas, na verdade, verifica-se empiricamente que isso nem sempre acontece. Então, torna-se incontornável perguntar o que estará a "salvar" muitos trabalhadores destas brutais ofensivas provenientes do palco laboral? A resposta da psicodinâmica do trabalho para esta embaraçosa questão é a de que os trabalhadores encontraram diferentes estratégias (individuais e/ou coletivas, estas últimas tendem a ser mais eficazes) para se protegerem da violência provinda das formas atuais em que se encontram as relações laborais e a organização do trabalho. Isto significa que alguns trabalhadores encontraram um meio para suportar e ajustar o sofrimento produzido pelo trabalho e, ainda assim, mantêm a aparente normalidade do seu funcionamento psíquico. Dejours (1991) empregou o conceito de estratégias defensivas para definir o 
"escudo protetor" utilizado pelos trabalhadores. De modo complementar, o autor refere que as estratégias de defesa são, por vezes, subtis, cheias de engenhosidade, diversidade e inventividade.

Contudo, apesar deste mecanismo defensivo ser normalmente bastante eficaz (evitando as supramencionadas descompensações psicopatológicas), é pertinente aludir que nem sempre funciona do modo desejado. Há situações em que os trabalhadores utilizam determinadas estratégias (escárnio, apologia da virilidade masculina, empatia, coesão do coletivo de trabalho, interajuda, solidariedade, etc.) para atenuarem o sofrimento inerente à exposição aos riscos ocupacionais de maior severidade e ao respetivo medo que lhe está subjacente; mas se, por exemplo, ocorrer um acidente de trabalho grave, este pode originar uma síndrome subjetiva pós-traumática, em que as estratégias defensivas que até ali tinham funcionado tornam-se ineficientes (DEJOURS; BÈGUE, 2009). Nestas situações, os riscos anteriormente renegados voltam à consciência com um impacto assustador. É importante sublinhar que a utilização deste tipo de armaduras — além de todos os benefícios que podem oferecer - também revelam o seu lado contraproducente. Na verdade, as estratégias defensivas podem funcionar como uma armadilha que insensibiliza os trabalhadores contra aquilo que os faz sofrer (DEJOURS, 1999). Isto é, servem para tolerar o intolerável. Não apenas para consigo, mas também para com o sofrimento dos outros. Uma outra forma de sofrimento associado ao trabalho é designada por sofrimento ético ${ }^{3}$. Este efeito de reprovação da consciência moral (ou de afronta aos valores sociais) pode ser denominado como traição do Ego, pelos psicanalistas, ou como dissonância cognitiva, pelos psicólogos.

No nível metodológico ${ }^{4}$, a abordagem da psicodinâmica do trabalho encontra-se bem sustentada para efetuar uma análise dos coletivos de trabalho desestruturados, a partir da realização de sessões de trabalho em grupo. Contudo, toda e qualquer metodologia tem potencialidades e limitações na observação do respetivo objeto de estudo. Embora seja relativamente raro, algumas pesquisas em psicodinâmica do trabalho recorrem a outras abordagens metodológicas diferentes da estrutura já mencionada, nomeadamente a observação participante, como foi o caso do estudo de Rolo (2013). Este aspeto amplia e enriquece a abordagem da psicodinâmica do trabalho, dado que permite observar as dinâmicas diretamente no local de trabalho e a partir de um ângulo em que as sessões de grupo terão mais dificuldade. No entanto, também a observação participante não estará isenta de subjetividade, dado que implica dimensões afetivas (ALMEIDA; PINTO, 1976). Na mesma linha de pensamento, Bourdieu (1989) refere que a observação participante talvez não seja mais do que uma falsa participação num grupo estranho.

\section{Trabalho prescrito e trabalho real}

A psicodinâmica do trabalho destaca a enorme diferença entre trabalho prescrito e trabalho real. $\mathrm{O}$ primeiro é designado como tarefa/coordenação, enquanto o segundo é denominado como atividade/cooperação. Este debate surgiu no seio da ergonomia ${ }^{5}$, mas rapidamente se estendeu a algumas áreas ligadas às ciências do trabalho, incluindo, naturalmente, a própria psicodinâmica do trabalho (AREOSA; SZNELWAR, 2019). Tal como já foi aludido, há, contudo, um aspeto central nesta dicotomia: a forma como o trabalho prescrito é imaginado/idealizado tende a ser substancialmente diferente da forma como ele é realizado na prática (designado como trabalho real). Esta abismal diferença entre ambas as conceções depende de múltiplos fatores; é precisamente sobre essas descoincidências que nós iremos nos debruçar em seguida.

Pode ainda haver um enorme campo por explorar relacionado com a forma como nós pensamos quando estamos a desempenhar as nossas funções laborais, nomeadamente recorrendo à abordagem dos dois sistemas de pensamento (STANOVICH; WEST, 2000; KAHNEMAN, 2012). É verdade que esta discussão está num outro paradigma, mas a psicodinâmica do trabalho ficaria enriquecida se utilizasse este conhecimento. Trabalhar é correr riscos e isso implica ter de gerir alguma incerteza. Normalmente o trabalho prescrito não considera as limitações da própria condição humana, logo, torna-se um fator potenciador de lapsos, erros, falhas e acidentes (AREOSA; DWYER, 2010). O trabalho prescrito é a forma como a entidade empregadora concebe e organiza o modo de realização do trabalho (tarefas a executar, tempos de trabalho, regras, normas, procedimentos, recursos materiais e humanos para cada função, tipo de máquinas utilizado etc.); em suma, é projetar como o trabalho deve ser feito. No entanto, o design do trabalho, por mais bem elaborado que esteja, nunca consegue prever todas as circunstâncias, constrangimentos, dificuldades e obstáculos que a sua realização prática pode implicar. Esta é a diferença crucial. Porém, é importante lembrar que todo o trabalho prescrito resultou sempre 
do trabalho real de alguém (CLOT, 1995). Para além disso, quando as regras e procedimentos são em grande número e custosas de aplicar (por exemplo, do ponto de vista cognitivo), isto significa que os executantes do trabalho prescrito dificilmente conseguem cumprir na íntegra o modelo que foi desenhado pela organização, mesmo que o quisessem fazer (recorrendo àquilo que se designa por greve de zelo ${ }^{6}$ ).

É a utilização do zelo por parte dos trabalhadores que permite recriar o trabalho e encontrar soluções para as dificuldades não previstas pelos mentores da organização do trabalho. Neste sentido o zelo é o ponto-chave para que haja produção (SZNELWAR et al., 2011). Mas, por vezes, isso implica ter de transgredir ordens ou instruções formais, de modo a construir regras que estejam em conformidade com a resistência imposta pelo trabalho real. É verdade que o trabalho real está, supostamente, destinado a adaptar-se ao prescrito, mas o que normalmente se pode observar é que o real vai transformar o prescrito. No entanto, ambos são indissociáveis. Isto significa que uma tarefa sem atividade corresponde a algo similar a uma máquina parada ou a instruções de trabalho guardadas numa gaveta. Por sua vez, uma atividade não relacionada com a tarefa pode ser comparada a palavras ou gestos sem qualquer sentido ou nexo (SZNELWAR, 2015). Será como tentar jogar um jogo sem conhecer as regras.

Trabalhar é também cooperar. Os coletivos de trabalho estão na base da cooperação, a qual procura corrigir e compensar as deficiências da organização do trabalho no plano da coordenação (ROLO, 2018). Para a psicodinâmica do trabalho a cooperação tem sempre uma dimensão positiva para a estruturação dos coletivos de trabalho. Porém, no sistema de produção capitalista, a cooperação pode ser vista, paralelamente, como uma dimensão coletiva do trabalho alienado (HAMRAOUI, 2014). Ainda assim, é pertinente referir que ao trabalho prescrito é acrescentada a inteligência dos trabalhadores para que as coisas funcionem. A aplicação desta inteligência é designada por trabalho vivo, o qual se torna imprescindível para o normal funcionamento de qualquer organização. Não há nenhuma organização que possa prescindir totalmente do trabalho vivo, pois se o fizessem estariam condenadas ao insucesso. Contudo, a partir deste ponto de vista, o trabalho vivo é, regra geral, um enigma, visto que não sabemos antecipadamente o que será necessário fazer para que funcione. É preciso recorrer à criatividade, empenho, esforço e sensibilidade dos trabalhadores. Atualmente, o nosso modelo de organização social baseado no capitalismo tem acentuado a transformação do trabalho vivo em trabalho morto (ANTUNES, 2008).

Voltando ainda aos motivos que estão por trás dos desvios efetuados pelos trabalhadores, é importante referir que sua ocorrência não significa que eles sejam na sua maioria imputáveis à vontade, autonomia ou liberdade de decisão dos próprios trabalhadores. Pelo contrário, a forma como está planeada a execução do trabalho pode estar subjugada por múltiplas questões organizacionais (impossibilidade técnica para executar certas tarefas, avarias em máquinas ou equipamentos cuja paragem seria recomendada pelo bom senso, mas que continuam a funcionar sem estar garantida a segurança; pressão para aumentar a produção; e por aí adiante); é também isto que pode implicar desvios ao trabalho prescrito.

Dentro deste contexto, Amalberti (1996) desenvolve um modelo denominado gestão cognitiva dinâmica ou compromisso cognitivo. Segundo o seu ponto de vista, os trabalhadores gerem permanentemente a sua atividade laboral através de um compromisso cognitivo entre riscos internos e riscos externos. Os primeiros são aqueles a que os trabalhadores aceitam sujeitar-se, enquanto os segundos estão relacionados com os diferentes ambientes de trabalho, onde se encontram várias categorias de risco, nomeadamente, riscos físicos, químicos, biológicos, ergonómicos ou psicossociais (AREOSA, 2014). Quando Amalberti (2016) defende que nem todos os desvios ao trabalho prescrito são necessariamente negativos, está a considerar de modo muito consistente alguns dos conhecimentos sobre a nossa forma de pensar quando estamos a trabalhar. No decorrer das suas atividades laborais alguns trabalhadores preferem efetuar desvios ao trabalho prescrito, quando sabem antecipadamente que esses erros não se traduzem em cenários ou consequências perigosas para a organização (ou para si próprios), do que ter de cumpri-lo à risca e ter de basear o seu funcionamento cognitivo em regras que tornam o trabalho mais lento, desgastante, fastidioso e que envolve recursos fatigantes. Aceitar determinados desvios considerados inconsequentes pode revelar-se uma gestão mais económica do ponto de vista cognitivo (AMALBERTI, 1996). Afinal, parece que o nosso cérebro não está programado, do ponto de vista evolutivo, para desperdiçar energias e recursos desnecessariamente. Estes saberes poderiam ser incorporados pela psicodinâmica do trabalho, no sentido de colmatar algumas das suas lacunas e insuficiências. 


\section{Atividade deôntica e reconhecimento}

Dejours (2013) defende que a construção e reconstrução de regras consomem uma parte significativa do nosso tempo e energia; esta condição é apelidada de atividade deôntica. As regras no trabalho nunca são apenas técnicas, são também sociais, pois implicam convivência. Normalmente o trabalho envolve uma relação com o outro, não é apenas produzir, é, sobretudo, um jogo de experiências em conjunto com o outro. Existem as regras que provêm do trabalho prescrito, as quais têm de ser complementadas pelas regras que emergem do trabalho real, as regras informais, as experiências e os saberes práticos dos trabalhadores. Se o trabalho real funciona bem são produzidos consensos no coletivo de trabalho. O somatório desses consensos transformase em novas regras de trabalho. A coesão dos coletivos de trabalho - que se constrói a partir da confiança recíproca - demonstra que os trabalhadores conhecem as regras, que as utilizam, que cooperam entre si, mas também que as conseguem contornar e ludibriar. Na verdade, não há regras universais que funcionem em todos os contextos, situações e circunstâncias. Há sempre as exceções, que necessitam de ser enfrentadas pela inteligência, criatividade e inventividade dos trabalhadores. Por outras palavras, precisam de utilizar o trabalho vivo. A coordenação que advém do trabalho prescrito necessita de ajustes efetuados no trabalho real (DEJOURS; GERNET, 2011).

Os trabalhadores que se recusam a fazer greve de zelo, aqueles que são pró-ativos com a organização do trabalho, esperam que esta atitude possa ser compensada. Anseiam que o seu contributo tenha uma retribuição; não somente uma recompensa material — indiscutivelmente importante, mas não a mais importante segundo as palavras de Dejours - acima de tudo esperam uma retribuição simbólica, cujo expoente máximo é o reconhecimento. O poder simbólico (recorrendo à expressão de Bourdieu (1989)) que é exercido pelo reconhecimento resulta, em parte, da mobilização subjetiva dos trabalhadores e do julgamento dos outros. Neste contexto, existem dois tipos de julgamentos no trabalho: 1) Aquele que é efetuado pelas hierarquias ou pelos beneficiários do trabalho, a partir de uma perspetiva mais utilitarista (utilidade técnica, económica ou social); e 2) Aquele que é preconizado pelos pares (é aqui que reside a beleza do trabalho). Este segundo tipo de julgamento diz respeito à conformidade do trabalho, da produção ou do serviço, ou seja, está relacionado com as artes do ofício (DEJOURS; BÈGUE, 2009). Paulatinamente, de reconhecimento em reconhecimento o trabalhador vai fortalecendo a sua identidade, a sua saúde e o seu bem-estar no trabalho, evitando deste modo uma maior vulnerabilidade aos riscos do seu trabalho (FACAS et al., 2015). O reconhecimento desempenha um papel crucial relativamente à prevenção do sofrimento no trabalho, pois confere significado aos esforços exercidos por cada trabalhador (ROLO, 2018), atribuindo dignidade ao próprio ato de trabalhar (WANDELLI, 2015).

É pertinente lembrar que o trabalho está profundamente relacionado com a realização do ego e que o fortalecimento da nossa identidade se constitui, em parte, como uma armadura da nossa saúde mental. O reconhecimento assume neste processo um papel extraordinário, dado que quando não há reconhecimento o mais provável é que o trabalho se resuma a uma expressão de alienação ou sofrimento. Por parte das organizações, poucos esforços têm sido feitos para minimizar o sofrimento relacionado ao ambiente laboral (LARA, 2011). A falta de reconhecimento no trabalho é suscetível de gerar um círculo vicioso de sofrimento, desestabilizador da identidade e tudo isto pode conduzir à doença mental.

\footnotetext{
Quando a qualidade de meu trabalho é reconhecida, também meus esforços, minhas angústias, minhas dúvidas, minhas decepções, meus desânimos adquirem sentido. Todo esse sofrimento, portanto, não foi em vão; não somente prestou uma contribuição à organização do trabalho, mas também fez de mim, em compensação, um sujeito diferente daquele que eu era antes do reconhecimento. O reconhecimento do trabalho, ou mesmo da obra, pode depois ser reconduzido pelo sujeito ao plano da construção da identidade. E isso se traduz afetivamente por um sentimento de alívio, de prazer, às vezes de leveza d'alma ou até de elevação (DEJOURS, 1999, p. 34).
}

No entanto, há, pelo menos, dois problemas associados ao reconhecimento. O primeiro decorre de o reconhecimento no trabalho estar a atravessar uma profunda crise, promovida pela introdução de novas técnicas de gestão ${ }^{7}$ nas organizações, as quais são cada vez mais perversas e desestruturantes. O segundo é quando o trabalhador já não consegue prescindir desse mesmo reconhecimento, enquanto pilar de suporte do seu ego e/ou da sua identidade. 


\begin{abstract}
Mas atenção, a psicodinâmica do trabalho pode também tornar-se uma armadilha. É o caso de quando, por uma identidade muito frágil, um trabalhador torna-se cativo dos julgamentos de reconhecimento pelo outro. Tudo se passa então como se os benefícios do reconhecimento não pudessem ser convenientemente apropriados pelo sujeito. Graças a seu trabalho, ele obtém gratificações materiais e narcísicas que lhe conferem robustez psíquica face aos conflitos. Mas, sob esse manto aparente, ele torna-se dependente desse reconhecimento, o qual ele não pode mais dispensar tendo em vista assegurar a sua continuidade identitária (DEJOURS, 2012, p. 368).
\end{abstract}

Para terminar a discussão deste aspeto reforça-se novamente a ideia de que o reconhecimento tem normalmente um papel positivo, pois serve para transformar o sofrimento resultante do trabalho em prazer, em consolidação do ego e em fortalecimento da identidade. Quando Dejours (2013) debate esta questão, entra profundamente no domínio psicanalítico, em que se aborda o conceito de sublimação, o qual tem sido alvo de inúmeros contributos por parte da psicodinâmica do trabalho.

\title{
Considerações Finais
}

Dadas as suas múltiplas consequências, os efeitos do trabalho sobre a saúde mental mereciam um maior destaque nas sociedades contemporâneas. Talvez ainda estejamos longe de conhecer o verdadeiro alcance e influência que o trabalho nos pode provocar, quer nos benefícios que oferece, quer nos aspetos prejudiciais que suscita (ou provavelmente um misto de ambas as situações). Evidentemente que a saúde mental depende de vários fatores (incluindo o nosso modelo económico, o capitalismo). Porém, apesar dos esforços e avanços propostos por algumas disciplinas, o trabalho, enquanto campo de investigação, é algo que epistemologicamente ainda está em aberto. Na realidade, os efeitos e as consequências do trabalho, ao nível biopsicossocial, são afinal uma caixa-negra longe de estar totalmente decifrada. O universo laboral ainda acarreta alguns enigmas e incorpora um lado obscuro, invisível ou submerso (tal como um iceberg do qual apenas se consegue observar a ponta). Na perspectiva de Dejours (2005) o conhecimento científico sobre complexidade humana nas situações de trabalho é ainda incompleto. Mas há uma certeza: o trabalho tanto pode gerar sofrimento, alienação, descompensações e mal-estar, como também satisfação, prazer, emancipação e reforço da identidade.

É também importante lembrar que o trabalho é algo que não parou de sofrer múltiplas evoluções ao longo dos tempos (ou retrocessos, em determinados casos) e que por isso mesmo carece de uma constante reavaliação. Para Dejours (1999) o nosso modelo de organização socioeconómico banalizou a injustiça social. O ideal de excelência preconizado por algumas técnicas de gestão tem consumado múltiplas formas de violência no trabalho (MONROY, 2000).

Ao longo do texto foi debatido que a psicodinâmica do trabalho está centrada na análise e descodificação da influência do trabalho sobre a saúde mental, quer do ponto de vista positivo, quer negativo. Esta disciplina tem contribuído de forma singular para compreender as diversas alterações, bem como as respetivas consequências, associadas às novas formas de organização do trabalho, particularmente aquelas que estão relacionadas com a saúde mental dos trabalhadores.

No presente estudo foram identificadas ainda ruturas significativas que podem conduzir os trabalhadores à morte, já não apenas por doença ocupacional ou acidente de trabalho, mas também por suicídio devido a descompensações mentais ou psicossociais (DEJOURS; BÈGUE, 2009; DEJOURS, 2017). Sem dúvida que este é um dos grandes dramas do mundo hodierno do trabalho.

\section{Referências}

ALMEIDA, J. F.; PINTO, J. M. A investigação nas ciências sociais. Lisboa: Editorial Presença, 1976.

AMALBERTI, R. Gestão da Segurança: Teorias e práticas sobre as decisões e soluções de compromisso necessárias. Presidente Prudente: Gráfica CS; Eireli; EPP, 2016.

AMALBERTI, R. La conduite des systèmes à risques. Paris, Presses Universitaires de France, 1996.

ANTUNES, R. Desenhando a nova morfologia do trabalho: As múltiplas formas de degradação do trabalho. Revista Crítica de Ciências Sociais, Coimbra, n. 83, p. 19-34, 2008. 
ANTUNES, R. O privilégio da servidão. São Paulo: Boitempo, 2018.

AREOSA, J. As percepções de riscos ocupacionais no sector ferroviário. Sociologia, Problemas e Práticas, n. 75, p. 83-107, 2014.

AREOSA, J. Capitalismo e precarização do trabalho. In: VELOSO, L. et al. (org.), Anarquismo, trabalho e sociedade. Coimbra: Almedina, 2017. p. 239-269.

AREOSA, J. O trabalho como palco do sofrimento. International Journal on Work Condition, n. 15, p. 81-95, 2018.

AREOSA, J.; DWYER, T. Acidentes de trabalho: uma abordagem sociológica. Configurações, n. 7, p. 107-128, 2010.

AREOSA, J.; SZNELWAR, L. Acidentes do trabalho: Alguns contributos da ergonomia e das ciências do trabalho, Revista do Tribunal Regional do Trabalho da $3^{\text {a }}$ Região, n. 100, p. 55-82, 2019.

BOURDIEU, P. O poder simbólico. Lisboa: Difel, 1989.

CLOT, Y. A função psicológica do trabalho. Petrópolis: Vozes, 2006.

CLOT, Y. Le Travail Sans L'homme? Pour une Psychologie des Milieux de Travail et de Vie. Paris: Edition La Découverte, 1995.

DEJOURS, C. A banalização da injustiça social. Rio de Janeiro: FGV Editora, 1999.

DEJOURS, C. A loucura do trabalho. São Paulo: Cortez, 1991.

DEJOURS, C. A sublimação, entre o sofrimento e prazer no trabalho. Revista Portuguesa de Psicanálise, Lisboa, n. 33, v. 2, p. 9-28, 2013.

DEJOURS, C. O fator humano. Rio de Janeiro: FGV Editora, 2005.

DEJOURS, C. Psicodinâmica do trabalho e teoria da sedução. Psicologia em Estudo, n. 17, v. 3, p. 363-371, 2012.

DEJOURS, C. Le choix, souffrir au travail n'est pas une fatalité. Montrouge, Fr: Bayard, 2015.

DEJOURS, C. Psicodinâmica do trabalho: casos clínicos. Porto Alegre: Dublinense, 2017.

DEJOURS, C.; BÈGUE, F. Suicide et travail: Que faire? Paris: Presses Universitaires de France, 2009.

DEJOURS, C.; GERNET, I. Trabalho, subjetividade e confiança. In: SZNELWAR, L. (org.), Saúde dos Bancários. São Paulo: Editora Gráfica Atitude, 2011. p. 33-43.

FACAS, E. et al. Sofrimento ético e (in)dignidade no trabalho bancário: análise clínica e dos riscos psicossociais. In: MONTEIRO M.; VIEIRA F.; MENDES A. M. (org.), Trabalho e prazer. Curitiba: Juruá, 2015. p. 233-256.

FREUD, S. Mal estar na civilização. Rio de Janeiro: Imago, 1997.

GANEM, V. Relato de uma experiência de terreno de intervenção em psicodinâmica do trabalho (PDT). Laboreal, n. 7, v. 1, p. 68-75, 2011.

GAULEJAC, V. Gestão como doença social: ideologia, poder gerencialista e fragmentação social. São Paulo: Ideias e Letras, 2007.

HAMRAOUI, É. Trabalho vivo, subjetividade e cooperação: aspectos filosóficos e institucionais. Cadernos de Psicologia Social do Trabalho., São Paulo, n. 17, p. 43-54, 2014.

HAN, B. C. Sociedade do cansaço. Petrópolis: Vozes, 2017.

KAHNEMAN, D. Pensar depressa e devagar. Lisboa: Temas e Debates, 2012.

LANCMAN, S. et al. Organização do trabalho, conflitos e agressões em uma emergência hospitalar na cidade de São Paulo, Brasil. Revista Terapia Ocupacional da Universidade de São Paulo, São Paulo, n. 23, v. 3, p. 199-207, 2012.

LARA, R. Saúde do trabalhador: considerações a partir da crítica da economia política. Revista Katálysis, Florianópolis, n. 14, v. 1, p. 78-85, 2011.

LIMA, S.; MENDES, A. M.; COSTA, M. F. Clínicas das patologias da sobrecarga no trabalho. In: MONTEIRO, J. K.; VIEIRA, F. O.; MENDES, A. M. (org.). Trabalho e prazer: teoria, pesquisas e práticas. Curitiba: Juruá Editora, 2015. p. 135-148.

LINHARES, A.; SIQUEIRA. M. Vivências depressivas e relações de trabalho: Uma análise sob a ótica da Psicodinâmica do Trabalho e da Sociologia Clínica. Cadernos EBAPE.BR, n. 12, p. 719-740, 2014.

MARX, K. Manuscritos econômico-filosóficos. São Paulo: Boitempo, 2010.

MENDES, A. M. Desejar, Falar, Trabalhar. Porto Alegre: Editora Fi, 2018.

MONROY, M. La Violence de l'Excellence: Pressions et contraintes en entreprise. Paris: Journal Des Psychologues, 2000.

ROLO, D. Contraintes organisationnelles, distorsion de la communication et souffrance éthique. Conservatoire National des Arts et Métiers, Paris, 2013.

ROLO, D. O trabalho: entre prazer e sofrimento. Techniques, Methodologies and Quality, n. 1, p. 28-38, 2018.

ROSSO, S. Mais trabalho! A intensificação do labor na sociedade contemporânea. São Paulo: Boitempo, 2008.

SENNETT, R. A corrosão do carácter: as consequências pessoais do trabalho no novo capitalismo. Lisboa: Terramar, 2001.

SENNETT, R. A cultura do novo capitalismo. Rio de Janeiro: Record, 2006.

STANDING, G. O precariado: a nova classe perigosa. Lisboa: Editorial Presença, 2014.

STANOVICH, K. E.; WEST, R. F. Individual differences in reasoning: Implications for the rationality debate? Behavioral and Brain Sciences, n. 23, v. 5, p. 645-665, 2000. 
SZNELWAR, L. et al. A subjetividade no trabalho em questão. Tempo social, n. 23, v. 1, p. 11-30, 2011.

SZNELWAR, L. Quando trabalhar é ser protagonista e o protagonismo no trabalho. São Paulo: Blucher, 2015.

WANDELLI, L. V. Da psicodinâmica do trabalho ao direito fundamental ao conteúdo do próprio trabalho e ao meio ambiente organizacional saudável. Revista Eletrônica do Curso de Direito da UFSM, Santa Maria, n. 10, p. 193-217, 2015.

WEBER, M. A Ética Protestante e o Espírito do Capitalismo. Barcarena: Editorial Presença, 2005.

\section{Notas}

1 No teatro laboral contemporâneo a subjetividade e a convivência deveriam ser consideradas variáveis tão importantes quanto a produção e a rentabilidade (GAULEJAC, 2007). A subjetividade é um dos aspetos centrais na abordagem da psicodinâmica do trabalho. Segundo Dejours, a afetividade é a base da subjetividade. Neste contexto, entende-se por afetividade a forma como o corpo vivencia o contato com o mundo exterior. Menosprezar ou desconsiderar a afetividade e a subjetividade é negar no homem a sua própria humanidade. "O essencial da subjetividade é da categoria do invisível. O sofrimento não se vê. Tampouco a dor. O prazer não é visível. Esses estados afetivos não são mensuráveis. São vivenciados de «olhos fechados». O fato de que a afetividade não possa jamais ser medida nem avaliada quantitativamente, de que ela pertença ao domínio das trevas, não justifica que se lhe negue a realidade nem que se despreze os que dela ousam falar de modo obscurantista. Ninguém ignora o que sejam o sofrimento e o prazer, e todos sabem que isso só se vivencia integralmente na intimidade da experiência interior" (DEJOURS, 1999, p. 29).

2 Vejamos como é perspectivada a origem da dualidade sofrimento/prazer no trabalho: "O sofrimento no trabalho começa quando, apesar de seu zelo, o trabalhador não consegue dar conta da tarefa. O prazer, ao contrário, começa quando, graças a seu zelo, o trabalhador consegue inventar soluções convenientes. Prazer e sofrimento no trabalho não são um suplemento de alma, eles são estritamente indissociáveis do trabalho" (DEJOURS, 2012, p. 364).

3 O sofrimento ético acontece quando o trabalhador é obrigado a praticar determinadas ações que condena moralmente, por causa do seu trabalho. É uma espécie de traição de si mesmo. Nas palavras de Dejours: "O novo capítulo do sofrimento ético torna mais compreensível uma segunda faceta da forma como «a nossa escala social de valores entra em linha de conta», a saber, o julgamento que o sujeito faz de si próprio, não só sobre a qualidade da sua contribuição no que concerne a produção, mas sobre o valor ético da sua prestação. Porque, pela sua atividade de produção, o trabalhador compromete, de facto, o destino de outro, em particular do cliente que tem obrigação de enganar ou do subordinado que deve «colocar sob pressão». Isto significa que o trabalho não se reduz a uma atividade, implica dimensões que advém da ação, no sentido que Aristóteles dá ao conceito de práxis: ação moralmente justa" (DEJOURS, 2013, p. 23).

4 Observe-se as principais características do método em psicodinâmica do trabalho (PDT): "Globalmente, o método de inquérito em PDT pode resumir-se da seguinte forma: a intervenção começa por um pré-inquérito que consiste em encontrar uma formulação adequada do pedido, visitar os locais de trabalho e obter todos os documentos úteis respeitantes à organização em questão, bem como aos conflitos que marcaram a sua história. O inquérito passa sempre pela constituição de pequenos grupos. Tal constituição obedece às categorias subjectivas definidas pelos intervenientes: o pedido e o seu conteúdo definem o grupo estudado. Os grupos são constituídos por voluntários, os quais se identificam a partir de uma reunião de informação na qual os intervenientes apresentam a intervenção a todo o pessoal. Os grupos assim constituídos participam em sessões colectivas de reflexão de meio dia de duração. Cada grupo reúne-se à razão de 2 a 4 sessões com um intervalo de 15 dias entre cada sessão. O material recolhido será depois reportado aos empregados numa sessão de um dia de duração consagrada à devolução oral. A leitura do relatório «palavra por palavra» será objeto de discussões até ser validado pelos participantes e pelos intervenientes. Os participantes são os primeiros destinatários desse relatório. Por fim, o relatório servirá de quadro de referência às discussões ulteriores visando a transformação da organização do trabalho" (GANEM, 2011, p. 69).

5 Vejamos como é esplanada esta diferença: "As descrições produzidas pelos ergonomistas permitem diferenciar a tarefa que corresponde aos objetivos a serem atingidos, e a atividade que corresponde àquilo que é feito concretamente pelo trabalhador na tentativa de atingi-los. Independentemente da precisão das instruções e das prescrições dadas pela organização do trabalho, sempre ocorrem imprevistos ou mau funcionamento, de tal maneira que o respeito escrupuloso das prescrições não permitiria que se atingissem os objetivos se um trabalhador delas não se distanciasse, não as transgredisse. Em outros termos, se as prescrições são respeitadas ao pé da letra, como numa "operação-padrão", nada funciona. Por outro lado, a criatividade, a cooperação e, ainda, a confiança, escapam de uma descrição e não podem ser prescritas. Para executar a tarefa designada é, então, necessário que o trabalhador demonstre engenhosidade, iniciativa e inventividade. O trabalho é, portanto, definido como o conjunto de atividades desenvolvidas por aqueles e aquelas que trabalham para enfrentar aquilo que não é prescrito pela organização do trabalho" (DEJOURS; GERNET, 2011, p. 34).

${ }^{6}$ O trabalho real é sempre muito mais rico e diversificado do que aquilo que os organizadores/mentores do trabalho prescrito conseguem prever. No mundo do trabalho há sempre incertezas, resistências, obstáculos, dificuldades, imprevistos, contradições 
ou incidentes. Por isso, é pertinente referir que trabalhar implica normalmente efetuar adaptações, fazer ajustes ou criar alternativas para, por exemplo, ultrapassar as dificuldades impostas por novas situações. Algumas vezes isso também implica não cumprir regras ou tentar contorná-las para que a execução do trabalho seja possível. Não é tanto uma resistência à autoridade hierárquica, é essencialmente para conseguir realizar o trabalho de forma eficiente. Nenhuma organização pode funcionar adequadamente sem que os seus trabalhadores utilizem este tipo de estratégias, pois a execução estrita das prescrições oficiais (ou seja, fazer greve de zelo) é condenar uma organização ao fracasso e ao insucesso. A título de exemplo, é referido o seguinte: "Se os enfermeiros executassem rigorosamente as ordens dos médicos, haveria muitos mortos nos hospitais, o que precisamente conseguem evitar graças ao seu zelo" (DEJOURS, 2013, p. 11).

7 A partir da década de 1980 começaram a surgir novas técnicas de gestão empresariais, as quais vieram degradar as relações de trabalho e aumentar o sofrimento. Estas novas práticas de gestão giram em torno de três eixos principais: 1) A avaliação individual de desempenho; 2) As técnicas ligadas à designada qualidade total (sistemas de certificação, círculos de qualidade, protocolos de atuação etc.); e 3) A subcontratação (que inibe a criação de coletivos de trabalho saudáveis ou desintegra os existentes e destrói a cooperação e a solidariedade entre trabalhadores). Uma das suas consequências mais graves é a sensação de isolamento aos quais os trabalhadores ficam remetidos. E o isolamento torna os trabalhadores mais vulneráveis ao sofrimento, dado que as estratégias defensivas coletivas estão corroídas. A título de exemplo, podemos referir que a qualidade total tem contribuído para a degradação das relações sociais de trabalho. Vejamos a opinião de uma assistente social cuja organização implementou um programa de qualidade total: "É preciso preencher fórmulas e seguir processos informatizados. Não temos mais tempo disponível para a escuta, porque temos cada vez mais indicadores de medida da atividade. Tenho a impressão de que a qualidade exigida pelas regras não corresponde àquilo que considero ser um trabalho de qualidade. O programa de qualidade impede-nos de trabalhar. Passamos mais tempo prestando contas daquilo que fazemos do que fazendo o que deveríamos. O procedimento é pesado e inaplicável" (GAULEJAC, 2007, p. 102-103).

\section{João Areosa}

joao.s.areosa@gmail.com

Doutor em Sociologia pelo Instituto Universitário de Lisboa (ISCTE)

Professor na Escola Superior de Ciências Empresariais (ESCE-IPS)

\section{ESCE-IPS}

Campus do IPS - Estefanilha 2910-761

Setúbal - Portugal

\author{
Agradecimentos \\ Não se aplica. \\ Agência financiadora \\ Não se aplica. \\ Contribuições dos autores \\ Não se aplica.
}

\author{
Aprovação por Comitê de Ética e consentimento para \\ participação \\ Não se aplica. \\ Consentimento para publicação \\ Consentimento do autor. \\ Conflito de interesses \\ Não há conflito de interesses.
}

